\title{
Sarcoidosis and granuloma genes: a family-based study in African-Americans
}

\author{
B.A. Rybicki*, M.J. Maliarik*, L.M. Poisson*, M.C. lannuzzi\#
}

Sarcoidosis and granuloma genes: a family-based study in African-Americans. B. A. Rybicki, M.J. Maliarik, L.M. Poisson, M.C. Iannuzzi. (C) ERS Journals Ltd 2004. ABSTRACT: The evidence for a genetic component in the aetiology of sarcoidosis includes familial aggregation, associations with genetic polymorphisms, and linkage to the major histocompatibility complex class region on chromosome $6 \mathrm{p}$. Unfortunately, the majority of genetic associations with sarcoidosis have not been consistently replicated.

In the present study, using a family-based study design, which controls for population stratification, the authors attempted to replicate previously reported associations between sarcoidosis and three attractive candidate genes studied primarily in casecontrol samples.

In 225 nuclear families, ascertained through African Americans with a history of sarcoidosis, no evidence was found for an association between sarcoidosis susceptibility and polymorphisms in the angiotensin converting enzyme, vitamin $D$ receptor and tumour necrosis factor- $\alpha$ genes. Further analyses of chronic and acute disease phenotypes failed to reveal any notable associations. Assuming an underlying inheritance model with an additive allelic effect on disease risk, the current study had $\sim 80-90 \%$ statistical power to detect a 3-fold increased risk associated with the putative risk allele of the polymorphisms under study.

The present authors conclude that in African-Americans, the angiotensin converting enzyme, vitamin $D$ receptor, and tumour necrosis factor- $\alpha$ genes are not significant risk factors for sarcoidosis susceptibility.

Eur Respir J 2004; 24: 251-257.
*Dept of Biostatistics and Research Epidemiology, Henry Ford Health System, Detroit, Michigan and ${ }^{\#}$ Division of Pulmonary, Critical Care, and Sleep Medicine, Mount Sinai Medical Center, New York, New York, USA

Correspondence: B.A. Rybicki, Dept of Biostatistics and Research Epidemiology, Henry Ford Health System, One Ford Place, 3E, Detroit, MI 48202, USA.

Fax: 13138746730

E-mail: brybick1@hfhs.org

Keywords: Calcitriol receptor genetic predisposition peptidyl-dipeptidase A polymorphism

Received: January 152004

Accepted after revision: April 92004

This study was supported by a National Institutes of Health grant R01 HL54306.
Sarcoidosis is a systemic granulomatous disease of unknown aetiology that can affect any organ system, but most frequently includes the lungs (in $\sim 90 \%$ of cases), skin and eyes. A genetic susceptibility to sarcoidosis has been supported by studies demonstrating familial clustering [1] and a higher prevalence of disease in first-degree relatives [2]. Clustering of cases within specific ethnic groups also suggests a genetic susceptibility. In the USA, African Americans have a higher disease incidence and morbidity compared with Caucasians [3]. The pathological hallmark of sarcoidosis is multinucleated noncaseating granulomas in affected organs. Granuloma burden is indicative of disease activity and longterm active disease can lead to fibrosis and organ dysfunction. Key genes that play a role in granuloma formation and persistence include angiotensin converting enzyme (ACE), tumour necrosis factor (TNF)- $\alpha$, and the vitamin $\mathrm{D}$ receptor (VDR).

The epithelioid cells in sarcoid-granulomas secrete $>40$ different cytokines and other mediators, including ACE [4]. Epithelioid cells of sarcoid granulomas contain ACE, and ACE synthesis in monocyte cell culture can be modulated by T-lymphocytes obtained from sarcoid patients [5]. Serum ACE levels in healthy individuals [6] and sarcoidosis patients [7] are influenced by a 287 base pair Alu sequence either present (insertion (I)) or absent (deletion (D)) in intron 16 of the ACE gene. Association studies of the ACE I/D polymorphism and sarcoidosis have produced mixed results. The ACE D allele, which is associated with higher serum ACE levels [6], has been found associated with increased sarcoidosis risk in African Americans [8], Japanese women [7] and in sarcoid-affected family members from a German population [9]. Conversely, other studies in both Caucasians $[10,11]$ and Japanese [12] have failed to find an association between the ACE I/D polymorphism and sarcoidosis susceptibility or progression.

TNF- $\alpha$ is a cytokine that probably has a key role in granuloma formation [13]. TNF- $\alpha$ is increased at sites of disease activity [14] and anti-TNF- $\alpha$ agents have shown promising therapeutic value in chronic sarcoidosis [15]. At least eleven polymorphisms in the promoter region of the TNF- $\alpha$ gene have been reported [16] but of these a $G$ to $A$ single base pair (bp) transition at position -307 is considered the most likely to affect gene transcription [16]. Several studies have examined this polymorphism in relation to sarcoidosis susceptibility [17-19], with a single case-control study in African Americans having null findings [20].

The active form of vitamin $\mathrm{D}, 1,25$-dihydroxyvitamin $\mathrm{D}_{3}$ $\left(1,25(\mathrm{OH})_{2} \mathrm{D}_{3}\right)$, a promoter of multinucleated giant cell formation [21], is produced at sites of sarcoid granulomas [22], and is elevated in sarcoidosis patients [23]. This hormone acts through the binding of intranuclear VDRs [24] and has been shown to interact directly with interferon gamma to promote the granulomatous process [25]. Several polymorphisms with potential functional significance have been identified in the VDR gene [26]. The Bsm I and Apa I polymorphisms are located in noncoding regions, whereas the Taq I polymorphism is in an exon but leads to a silent codon change with the nucleotides ATT and ATC both coding for 
isoleucine at codon 352. The $b$ allele of the Bsm I polymorphism, which has a reported association with sarcoidosis susceptibility [27], is in strong linkage disequilibrium with the absence of a Taq I cleavage site ( $T$ allele) in both Caucasians and African-Americans [28]. Another DNA sequence variant in the VDR gene is a thymine/cytosine (T/C) polymorphism in the first of two potential start (ATG) codons detected by restriction fragment length polymorphism using the endonuclease $F o k$ I. The functional significance of the Fok I polymorphism is uncertain. However, most data indicate that the $F$ allele, which lacks the first ATG start codon resulting in a transcribed protein three amino acids shorter than the variant $f$ allele, is more effective in transactivation of the $1,25(\mathrm{OH})_{2} \mathrm{D}_{3}$ signal [29]. One study has reported an association of the $f$ allele with tuberculosis [30].

Since conflicting case-control reports of sarcoidosis associations with variants in the ACE, VDR and TNF- $\alpha$ genes exist, the present authors attempted to replicate these associations in a family-based study of sarcoidosis in AfricanAmerican nuclear families. The strength of the family-based design is that it controls for genetic background unrelated to disease. While case-control samples are generally easier to collect and are statistically more powerful than family-based samples under some circumstances [31], case-control samples can produce spurious associations because of ethnic admixture or other problems relating to inappropriate controls [32]. Therefore, the results presented here should help clarify the role of the ACE (I/D), VDR (TaqI and Fok I) and TNF- $\alpha$ $(-307)$ genetic polymorphisms with regard to sarcoidosis risk in African Americans.

\section{Methods}

\section{Study sample}

The study protocol was approved by the Henry Ford Hospital Institutional Review Board. Diagnosis was confirmed by tissue biopsy in $86 \%$ of the index cases and in all cases with normal (stage 0) chest radiographs. The cases without histological confirmation had radiographical evidence of bilateral hilar adenopathy, a compatible clinical presentation and were observed for $\geqslant 2$ yrs with no other medical condition that could explain the clinical course.

From a total of 623 eligible probands, 359 (58\%) were enrolled with one or more first-degree family member(s). Of these, 234 had two or more parents or sibs that donated a blood sample. An additional 10 African-American sarcoidosis families were recruited outside the Henry Ford Health System, resulting in 244 total families. Both parents were genotyped when available. When one or both parents were unavailable for genotyping, all available full sibs were genotyped. Using a panel of unlinked markers, 20 families $(8.2 \%)$ with Mendelian segregation inconsistencies and two families $(0.8 \%)$, where the proband, after further follow-up, was not found to have sarcoidosis, were excluded from the analysis. Three of the remaining 222 families had two separate nuclear families, which were analysed separately, resulting in 225 nuclear families or a total of 704 individuals for study. The three basic family configurations are shown in table 1 . While the majority of family members with a sarcoidosis history were probands through whom the family was ascertained, there were also 22 sibs and four additional family members (who were treated as index cases in the analysis) with a history of sarcoidosis based on self-report of a physician diagnosis of this condition. In 18 of the $22 \mathrm{sib}$ cases, and the other four additional family member cases, the diagnosis was confirmed by biopsy. In the remaining four sib cases, a medical record
Table 1.-Breakdown of the different family configurations of the 225 African-American sarcoidosis nuclear families in the study population

$\frac{\text { Number of affected offspring }}{1}$

\begin{tabular}{llr}
\hline Family configurations & & \\
Both parents & $43(19.1)$ & $2(0.9)$ \\
1 parent, $\geqslant 2$ offspring & $97(43.1)$ & $7(3.1)$ \\
No parents, $\geqslant 3$ offspring & $66(29.3)$ & $10(4.4)$ \\
\hline
\end{tabular}

Data are presented as $\mathrm{n}(\%$ total $)$.

review revealed a chest radiograph report of bilateral hilar adenopathy at the time of diagnosis. Most families $(90 \%)$ had a single affected offspring and $>80 \%$ of families had additional unaffected sibs.

\section{Phenotyping}

Using a previously described criteria used for organ system involvement [33], affected sibs were phenotypically categorised under three broad categories: mild, moderate, or severe. Mild cases were asymptomatic or had normal organ systems without treatment, or spontaneously resolved to normal within 2 yrs of presentation. Moderate cases had a symptomatic disease course with minimal residual abnormality in any organ with or without treatment, or a disease course for $>3$ yrs with some residual abnormality despite therapy. Severe cases had progressive organ dysfunction for $\geqslant 3$ yrs, despite therapy.

\section{Genotyping}

High molecular weight DNA was isolated from anticoagulated blood by detergent lysis and organic extraction. The diallelic ACE polymorphism was genotyped by enzymatic amplification of a segment within intron 16 with the 190 and 490 base pair alleles resolved by $6 \%$ polyacrylamide gel electrophoresis. The primers were designed as previously described [8]. Amplification was performed using $100 \mathrm{ng}$ of genomic DNA and 10 picomol (pmol) of each primer at $94^{\circ} \mathrm{C}$ for $1 \mathrm{~min}, 58^{\circ} \mathrm{C}$ for $1 \mathrm{~min}$ and $72^{\circ} \mathrm{C}$ for $2 \mathrm{~min}$, for 30 cycles. To confirm that genotypes with only a D band were true homozygotes rather than mistyped ID heterozygotes due to preferential amplification of the $\mathrm{D}$ allele, a second reaction was performed using the sense primer labelled with gamma $\left.{ }^{32} \mathrm{P}\right]$ ATP. Alleles were separated by acrylamide gel electrophoresis, stained with ethidium bromide to display molecular weight markers and autoradiographed to detect alleles.

The VDR Taq I and Fok I polymorphisms were typed by amplification and restriction fragment length polymorphism as previously described [30]. Taq I identifies a silent $\mathrm{T}$ to $\mathrm{C}$ base change at nucleotide 352 . Fok I identifies a $\mathrm{C}$ to $\mathrm{T}$ transition that creates an alternative initiation site three codons upstream from a second ATG start site. Alleles were separated by agarose gel electrophoresis, and detected with ethidium bromide. Each DNA sample was assayed at least twice per marker, to confirm genotype.

The $\mathrm{G}$ to $\mathrm{A}$ transition at position -307 of the TNF- $\alpha$ gene was determined by amplification of a $413 \mathrm{bp}$ region incorporating two polymorphisms. Amplification was performed using the sense primer 5'-TTCCTGCATCCTGTCTGGAA-3' and antisense primer, 5'-AGGGAGCGTCTGA-TGGCTG-3' at 1 pmol per reaction, $2 \mathrm{mM}$ deoxynucleotidetriphosphates, 10 ng DNA, and 0.62 unit Taq DNA polymerase (Promega, 
Table 2.-Association between the angiotensin converting enzyme (ACE) insertion (I)/deletion (D), vitamin D receptor (VDR) Fok I and Taq I, and tumour necrosis factor (TNF)-307 polymorphisms and sarcoidosis susceptibility in AfricanAmericans families based on a multiallelic test using the Family-Based Association Test software

\begin{tabular}{lccccc}
\hline Polymorphism & \multicolumn{2}{c}{ Dominant model $^{\#}$} & & \multicolumn{2}{c}{ Additive model $^{\Phi}$} \\
\cline { 2 - 3 } \cline { 5 - 6 } & \multicolumn{2}{c}{ Chi-squared test } & p-value & Chi-squared test & p-value \\
\hline ACE I/D & 2.22 & 0.33 & & 0.06 & 0.81 \\
VDR Fok I & 0.89 & 0.64 & & 0.01 & 0.91 \\
VDR Taq I & 0.02 & 0.99 & & $<0.01$ & 0.95 \\
TNF-307 & 0.34 & 0.84 & & $<0.01$ & 0.98 \\
\hline
\end{tabular}

\#: 2 degrees of freedom; ${ }^{\uparrow}: 1$ degree of freedom.

Madison, WI, USA). Amplification conditions were $94^{\circ} \mathrm{C}$ for $60 \mathrm{~s}, 62^{\circ} \mathrm{C}$ for $60 \mathrm{~s}, 72^{\circ} \mathrm{C}$ for $60 \mathrm{~s}$, with a final extension step of $6 \mathrm{~min}$ at $72^{\circ} \mathrm{C}$. Products were sequenced in both directions on a Beckman CEQ 2000XL, by the CEQ Dye Terminator Cycle Sequencing kit, according to the manufacturer's protocol (Beckman Coulter, Fullerton, CA, USA). All genotypes were performed in duplicate with genotypes in disagreement $(\sim 10 \%)$ run a third time to verify results.

\section{Statistical methodology}

To determine whether one or more alleles at the locus of interest was associated with the sarcoidosis phenotype, a Family-Based Association Test (FBAT) statistic, S, calculated using the FBAT software was used [34]. In short, this test statistic determines whether a certain allele in a nuclear family is transmitted to affected offspring more (or less) often than would be expected under Mendelian segregation. Test statistics for both dominant and additive inheritance models were computed. The outcome for initial analyses was a dichotomous affection status variable. More in depth phenotype models were also examined in which the three phenotypic levels were treated as either a dichotomous or an ordinal variable. For the former parameterisation, a multivariate model was used where three 0,1 dummy variables were coded corresponding to absence or presence of the phenotype in question. For the latter parameterisation, affected sibs were coded as 1, 2 or 3 with a higher number corresponding to a more severe phenotypic level. For both types of parameterisations, unaffected sibs were coded as zero.
The statistical power of the study sample for detecting an association between the putative risk allele of each polymorphism and sarcoidosis was calculated with the power calculation of Family-Based Test software [35]. Power calculations were conditional on the frequency of each risk allele, an estimated lifetime risk of $1 \%$ [3], the study sample configuration depicted in table 1 and a range of genotype relative risks $(\gamma \mathrm{s})$. Using these parameters, expected genotypicspecific penetrance values, $\mathrm{f}_{2}$ (two risk alleles), $\mathrm{f}_{1}$ (one risk allele), and $\mathrm{f}_{0}$ (no risk alleles), under additive $\left(\mathrm{f}_{0}=2 \mathrm{f}_{1}-\mathrm{f}_{2}\right)$, multiplicative $\left(\mathrm{f}_{0}=\mathrm{f}_{1}^{2} / \mathrm{f}_{2}\right)$ and dominant $\left(\mathrm{f}_{1}=\mathrm{f}_{2}\right)$ inheritance models could be calculated. The routine used to compute power estimates for the family-based analysis was based on a second-order Taylor expansion, which has been shown to have good precision for samples sizes of $\geqslant 100$ families [35].

\section{Results}

Multiallelic test statistics for the four polymorphisms tested, ACE I/D, VDR Fok I and Taq I, and TNF-307 are shown in table 2 . Statistical p-values did not reach significance $(\mathrm{p}=0.05)$ for either dominant or additive models of inheritance. Table 3 shows the biallelic association tests for the putative risk allele of each polymorphism. In table 3 , both the observed and expected values of allelic transmissions, $\mathrm{S}$ and $\mathrm{E}(\mathrm{S})$, respectively, are based on the genetic model postulated. Computation of the variance of $\mathrm{S}$, allowed estimation of a significance level for a large number of families based on a $\mathrm{Z}$ statistic, which is normally distributed with mean 0 and variance 1 , and defined as:

$$
\mathrm{Z}=[\mathrm{S}-\mathrm{E}(\mathrm{S})] / \sqrt{ } / \text { Variance }(\mathrm{S})
$$

Under both dominant and additive models of inheritance, none of the four alleles markedly deviated from the null hypothesis. Since it is possible that the polymorphisms under study could be risk factors for disease progression rather than susceptibility, the outcome of disease phenotype was analysed next instead of affection status. Phenotype data were available for sibs in 163 of the $225(72 \%)$ study families. Table 4 depicts four different types of analyses based on inheritance models (dominant and additive) and phenotypic parameterisations. While no statistically significant results were observed, the VDR Fok I polymorphism had a marginally significant result $(\mathrm{p}=0.08)$ under an additive model with a multivariate phenotype. For the dichotomous phenotypic outcome, no assumptions were made as to the relationship of one phenotypic category with another, as compared with the

Table 3. - Association between selected alleles of the angiotensin converting enzyme (ACE) insertion (I)/deletion (D), vitamin D receptor (VDR) Fok I and Taq I and tumour necrosis factor (TNF)-307 polymorphisms and sarcoidosis susceptibility in AfricanAmericans families based on a biallelic test using the Family-Based Association Test software

\begin{tabular}{lcccccrrr}
\hline Polymorphism*allele & Allele frequency $\%$ & Ninf & S & E(S) & S/E(S) & Variance (S) & Z score & p-value \\
\hline Dominant model & & & & & & & \\
ACE I/D*D & 58.7 & 51 & 105 & 108.1 & 0.97 & 12.9 & -0.85 \\
VDR Fok I*f & 23.9 & 75 & 62 & 59.7 & 1.04 & 18.3 & 0.53 \\
VDR Taq I*t & 27.2 & 100 & 70 & 70.6 & 0.99 & 24.9 & -0.11 \\
TNF-307*A & 14.3 & 44 & 35 & 35.9 & 0.97 & 10.7 & -0.26 \\
Additive model & 58.7 & 116 & 160 & 158.5 & 1.01 & 43.3 & 0.79 \\
ACE I/D*D & 23.9 & 88 & 73 & 72.4 & 1.01 & 27.6 & 0.24 \\
VDR Fok I*f & 27.2 & 109 & 80 & 80.4 & 1.00 & 33.2 & 0.11 \\
VDR Taq I*t & 14.3 & 56 & 45 & 44.9 & 1.00 & 16.4 & 0.91 \\
TNF-307*A & & & & & & 0.06 \\
\end{tabular}

Data are presented as $n$ unless otherwise stated. Ninf: number of informative families; S: number of observed allelic transmissions; E(S): expected number of allelic transmissions under stated model of inheritance. Both observed and expected values of allelic transmissions, $\mathrm{S}$ and $\mathrm{E}(\mathrm{S})$, respectively, are based on the genetic model postulated. Computation of the variance of $S$, allowed estimation of a significance level for a large number of families based on a $Z$ statistic, defined as $Z=[S-E(S)] / \sqrt{ }$ variance $(S)$, which is normally distributed with mean 0 and variance 1 . 
Table 4. - Association between the angiotensin converting enzyme (ACE) insertion (I)/deletion (D), vitamin D receptor (VDR) Fok I and Taq I, tumour necrosis factor (TNF)-307 and polymorphisms and sarcoidosis disease severity in African-American families based on a multiallelic test using the Family-Based Association Test software

\begin{tabular}{|c|c|c|c|c|}
\hline \multirow[t]{2}{*}{ Polymorphism } & \multicolumn{2}{|c|}{ Dichotomous phenotype ${ }^{\#}$} & \multicolumn{2}{|c|}{ Ordinal phenotype } \\
\hline & Chi-squared (dof) & p-value & Chi-squared (dof) & p-value \\
\hline \multicolumn{5}{|l|}{ Dominant model } \\
\hline ACE I/D & $4.71(5)$ & 0.45 & $3.48(2)$ & 0.18 \\
\hline VDR Fok I & $5.59(3)$ & 0.13 & $3.64(2)$ & 0.16 \\
\hline VDR $T a q \mathrm{I}$ & $0.74(3)$ & 0.86 & $0.28(2)$ & 0.87 \\
\hline TNF-307 & $1.19(2)$ & 0.55 & $0.50(2)$ & 0.78 \\
\hline \multicolumn{5}{|l|}{ Additive model } \\
\hline ACE I/D & $0.35(3)$ & 0.95 & $0.35(1)$ & 0.62 \\
\hline VDR Fok I & $5.06(2)$ & 0.08 & $0.06(1)$ & 0.80 \\
\hline VDR $T a q$ I & $1.02(3)$ & 0.80 & 0.01 (1) & 0.93 \\
\hline TNF-307 & $0.64(2)$ & 0.73 & 0.08 (1) & 0.78 \\
\hline
\end{tabular}

Data are presented as Chi-squared values unless otherwise stated. dof: degrees of freedom. ${ }^{*}$ : The dichotomous phenotype was parameterised 1,0 in a four-level multivariate model; ": The ordinal phenotype was parameterised as $0,1,2$ and 3 with each increasing level representing a greater level of disease severity.

ordinal phenotypic outcome that was modelled such that increasingly severe phenotypic categories had higher covariate values. Among the phenotyped-affected sibs, the VDR Fok ${ }^{*} f$ allele had an increasingly higher frequency by severity of phenotypic category, i.e. $33.8 \%$ in mild cases, $42.5 \%$ in moderate cases and $51.7 \%$ in severe cases. The frequency of the VDR $F o k^{*} f$ allele among the unaffected sibs in these families was $41.3 \%$.

Since the presented results were largely negative, the current authors next tested what statistical power the present study sampled afforded. Statistical power was calculated for the putative risk allele of each of the four polymorphisms under study. For each allele and inheritance model combination, genotype relative risks $(\gamma)$ ranging $1-5$ were tested at the type I error $(\alpha)$ levels of 5 and $1 \%$ (fig. 1). For the ACE I/D*D allele, $\gamma$ s of $\geqslant 3$ were detected at the $\alpha=0.05$ level with $\sim 80 \%$ statistical power under an additive inheritance model, and with $90 \%$ statistical power under a multiplicative inheritance model. At the $\alpha=0.01$ level for the additive and multiplicative models, $\gamma \mathrm{s}$ of $\geqslant 4$ could be detected with $\geqslant 80 \%$ power depending on the inheritance model. Under a dominant inheritance model, the statistical power only approached $60 \%$ for a $\gamma$ value of 5 at $\alpha=0.05$. For the VDR Fok I* $f$ and Taq I*t alleles, $\gamma \mathrm{s}$ of $\geqslant 3$ were detected at the $\alpha=0.05$ level with $\geqslant 90 \%$ statistical power under all three inheritance models tested. Likewise $\gamma \mathrm{s}$ of $\geqslant 3$ could be detected with $\geqslant 70 \%$ statistical power under all three inheritance models tested at the $\alpha=0.01$ level. Statistical power for $\gamma \mathrm{s}$ of $\geqslant 4$ could be detected with $\sim 100 \%$ power under all three inheritance models tested at both $\alpha$ levels $(0.01$ and 0.05$)$ tested. Statistical power estimates for the TNF-307* $A$ allele were virtually identical to the two VDR alleles under the dominant and additive inheritance models and slightly less under the multiplicative inheritance model.

\section{Discussion}

Noncaseating granulomas are the histological hallmark of sarcoidosis, therefore, the present study investigated polymorphisms in candidate genes probably involved in granuloma formation and maintenance. Conflicting case-control study results with respect to sarcoidosis risk exist for polymorphisms in the ACE [7-12, 36-40], VDR [27, 41], and TNF- $\alpha[17-20,42]$ genes (table 5). Therefore, the current authors tested polymorphisms in these genes for associations with sarcoidosis in African-American families. Although the present study had sufficient statistical power to detect effect sizes of $\geqslant 3$ under an additive inheritance model, no significant associations were found.

One possible reason for the inconsistent results across sarcoidosis genetic association studies could be case heterogeneity. Inclusion of misdiagnosed cases will bias results towards the null hypothesis, but an unrepresentative case group can either artificially increase or decrease an odds ratio. Many sarcoidosis studies rely on cases drawn from specialised clinics that treat more severe and advanced cases. If any of these polymorphisms are truly related to sarcoidosis progression or disease subtypes, as several studies report for the ACE $[8,36]$ and TNF- $\alpha[17,42]$ polymorphisms, then a disproportionate mix of disease types among cases may bias an odds ratio measuring sarcoidosis susceptibility. In the present study population most cases were phenotyped, so the present authors were able to examine the relationship between the four polymorphisms under study and disease severity. No association was found between either the ACE I/D or TNF307 polymorphisms and disease phenotype, which would suggest that neither of these polymorphisms are related to disease progression in African Americans and that the case mix in the present study population did not influence its susceptibility results. If the TNF-307 polymorphism is actually a marker for Lofgrens syndrome and erythema nodosum in sarcoidosis, as several studies report [17, 42], then these conditions being rare in African-American sarcoidosis cases [43] may explain the negative findings with respect to this polymorphism in the current study. However, the extent to which the current authors could exclude a disease progression gene was limited by a smaller sample size due to missing and incomplete phenotype data, which did not allow the present study to consider the full range of phenotypic expressions the genes under study could exhibit.

Genetic and environmental background can also affect case-control genetic association results. All four polymorphisms that were studied are observed in Caucasian, Japanese and African-American populations but their effect on disease susceptibility may be altered by other genetic or environmental factors. If these factors vary among ethnic groups, then ethnic-specific associations of a given polymorphism with sarcoidosis susceptibility are possible.

In the study by NIIMI et al. [27], the Bsm I $B$ allele was overrepresented in sarcoidosis patients but GULEVA and SEITZER [41] subsequently reported a failure to replicate this finding in a German Caucasian population. In the current study population, the corresponding $t$ allele for the Taq I 

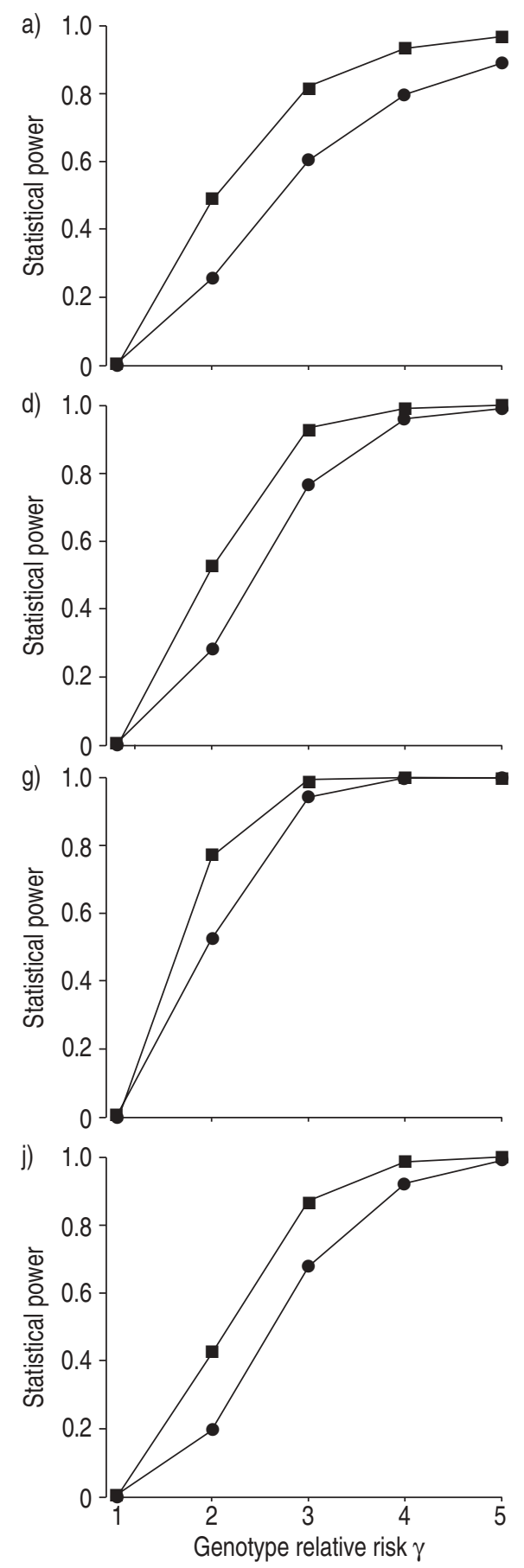

b)

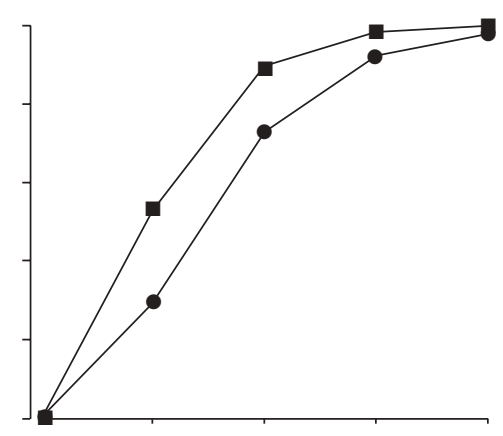

e)

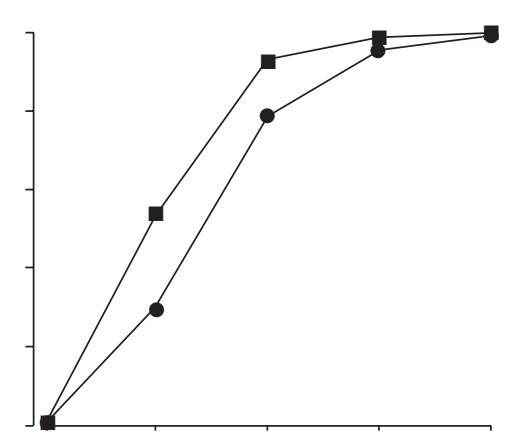

h)

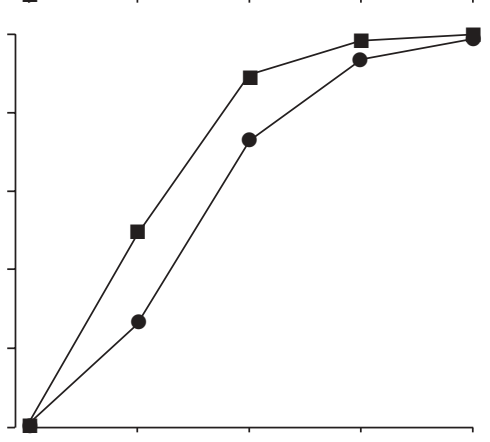

k)

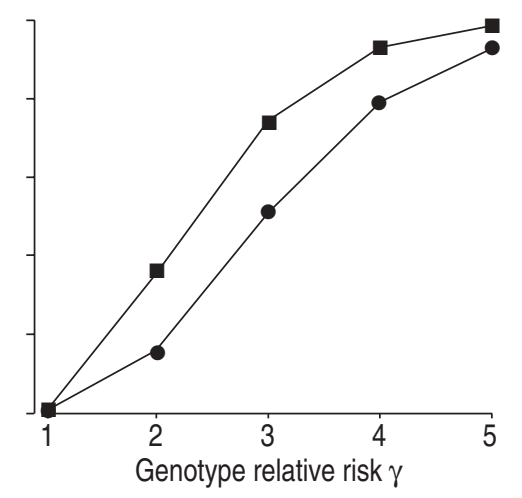

c)

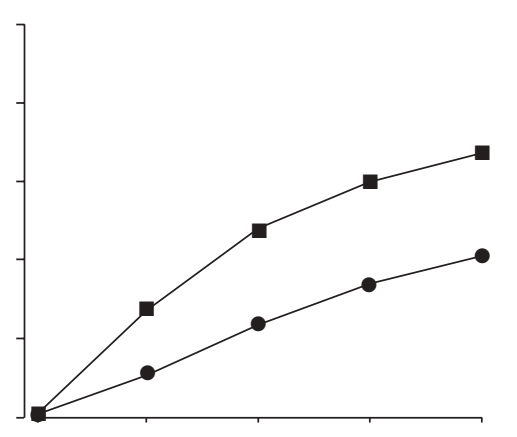

f)

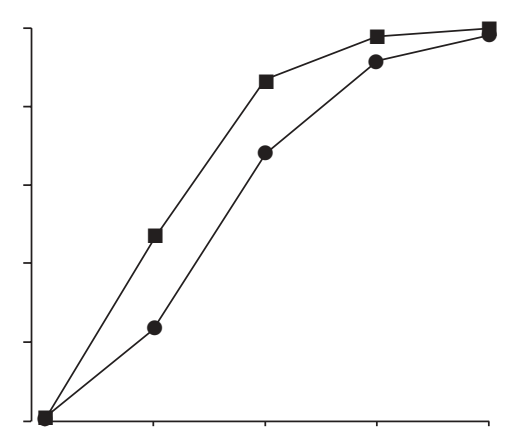

i)

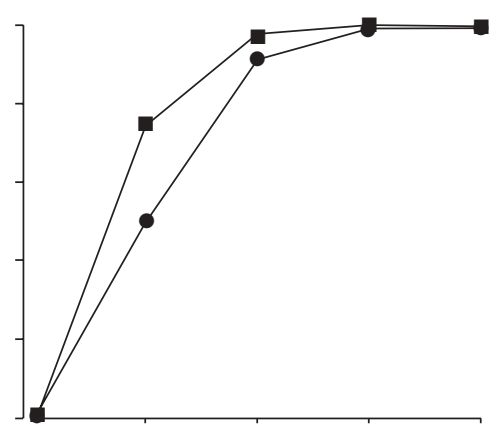

I)

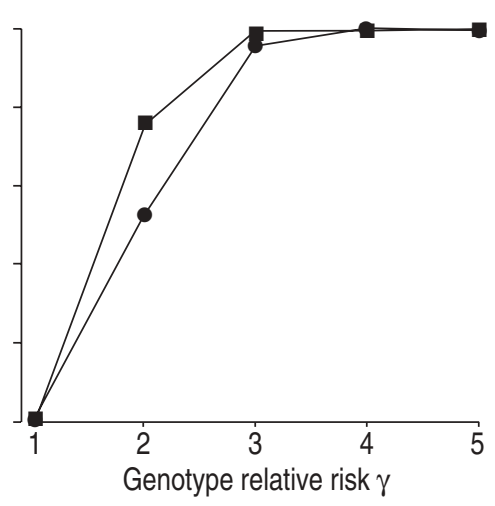

Fig. 1. - Statistical power estimates for the angiotensin converting enzyme (ACE) insertion (I)/ deletion (D)* $D$ allele (a-c), vitamin D receptor (VDR) Fok $\mathrm{I}^{*} f(\mathrm{~d}-\mathrm{f})$, VDR Taq $\mathrm{I}^{*} t(\mathrm{~g}-\mathrm{i})$ and tumour necrosis factor $(\mathrm{TNF})-307^{*} A(\mathrm{j}-1)$ alleles to detect genotype relative risks $(\gamma)$ ranging $1-5$ under additive ( $\mathrm{a}, \mathrm{d}, \mathrm{g}$ and $\mathrm{j}$ ), multiplicative (b, e, h and $\mathrm{k}$ ) and dominant inheritance (c, f, i and $\mathrm{l}$ ) models and type I error levels of 0.05 ( and $0.01(\bullet)$.

polymorphism showed no preferential transmission to affected offspring. The current study also examined the Fok I VDR polymorphism, which is in linkage equilibrium with the Taq I/Bsm I allele group [30], and found that this polymorphism was not associated with sarcoidosis susceptibility but the variant $f$ allele may have a modest association with chronic sarcoidosis. The potential functional relevance of the Fok I polymorphism [29] and the association of VDR genotypes with other granulomatous disorders [44, 45] would suggest that the VDR gene warrants further investigation in sarcoidosis. However, in terms of sarcoidosis susceptibility both VDR alleles tested in the present study had an $80 \%$ power to detect a 2-fold increased risk under a dominant model, which is the risk level for the heterozygote VDR Bsm I polymorphism previously reported [27].

The extent to which population stratification biases results of case-control genetic association studies is a debated topic. While in theory, selection of a control sample from the same population that cases are drawn should avoid population stratification, in practice uniform case/control sampling is difficult to achieve. Statistical methods to adjust for population stratification using population-specific alleles 
Table 5. - Summary of case-control studies of sarcoidosis susceptibility in relation to angiotensin converting enzyme (ACE) insertion (I)/deletion (D), tumour necrosis factor (TNF)-307 and vitamin D receptor (VDR) gene polymorphisms

\begin{tabular}{|c|c|c|c|c|c|}
\hline Polymorphism [reference] & Population & Risk allele ${ }^{\#}$ & Cases/controls & ORHet $(95 \% \mathrm{CI})$ & ORHom $(95 \% \mathrm{CI})$ \\
\hline \multicolumn{6}{|l|}{$\mathrm{ACE}(\mathrm{I} / \mathrm{D})$} \\
\hline ARBUSTINI [11] & Italian Whites & 0.60 & $61 / 80$ & $0.54(0.20-1.49)$ & $1.03(0.37-2.91)$ \\
\hline FURUYA [7] & Japanese & 0.33 & $103 / 341$ & $1.69(1.04-2.73)$ & $1.37(0.68-2.75)$ \\
\hline GARRIB [37] & UK Whites & 0.47 & $54 / 100$ & $2.38(0.88-6.44)$ & $4.50(1.53-13.25)$ \\
\hline \multirow[t]{2}{*}{ MALIARIK [8] } & US Whites & 0.58 & $60 / 49$ & $0.66(0.23-1.90)$ & $0.50(0.16-1.61)$ \\
\hline & US Blacks & 0.44 & $183 / 111$ & $1.30(0.72-2.36)$ & $3.17(1.50-6.71)$ \\
\hline \multirow[t]{2}{*}{ MCGRATH [10] } & UK Whites & 0.54 & $180 / 386$ & $0.92(0.59-1.44)$ & $0.86(0.53-1.40)$ \\
\hline & Czech Whites & 0.47 & $56 / 179$ & $0.74(0.36-1.49)$ & $1.02(0.45-2.33)$ \\
\hline PAPADOPOULOS [38] & Swedish Whites & 0.52 & $62 / 107$ & $0.51(0.23-1.11)$ & $0.91(0.39-2.12)$ \\
\hline PIETINALHO [36] & Finnish & 0.51 & $59 / 70$ & $1.78(0.69-4.56)$ & $1.79(0.64-5.03)$ \\
\hline SHARMA [39] & UK Whites & 0.52 & $47 / 146$ & $1.36(0.58-3.18)$ & $1.33(0.54-3.30)$ \\
\hline TAKЕМOTO [40] & Japanese & 0.37 & $100 / 247$ & $1.44(0.87-2.38)$ & $0.80(0.38-1.69)$ \\
\hline TOMITA [12] & Japanese & 0.35 & $207 / 314$ & $1.28(0.88-1.88)$ & $1.31(0.75-2.29)$ \\
\hline \multicolumn{6}{|l|}{ TNF-307 } \\
\hline \multirow[t]{2}{*}{ GRUTTERS [17] } & UK Whites & 0.19 & $96 / 354$ & $1.10(0.68-1.80)$ & $1.28(0.40-4.10)$ \\
\hline & Dutch Whites & 0.21 & $100 / 222$ & $0.89(0.54-1.49)$ & $0.63(0.17-2.37)$ \\
\hline \multirow[t]{2}{*}{ PANDEY [20] } & US Whites & 0.17 & $278 / 278$ & $1.16(0.81-1.68)$ & $1.32(0.51-3.42)$ \\
\hline & US Blacks & 0.14 & $219 / 219$ & $1.11(0.72-1.71)$ & $0.25(0.03-2.29)$ \\
\hline SEITZER [19] & German Caucasians & 0.19 & $101 / 216$ & $1.13(0.67-1.92)$ & $1.85(0.70-4.90)$ \\
\hline YAMAGUCHI [18] & Japanese & 0.01 & $110 / 161$ & $1.47(0.20-10.61)$ & $1.47(0.20-74.76)$ \\
\hline \multicolumn{6}{|l|}{ VDR } \\
\hline NIIMI [27] & Japanese & 0.11 & $101 / 105$ & $2.42(1.29-4.53)$ & $1.34(0.08-21.82)$ \\
\hline GULEVA [41] & European & 0.32 & $85 / 80$ & $0.86(0.45-1.64)$ & $0.72(0.25-2.27)$ \\
\hline
\end{tabular}

Data are presented as $\mathrm{n}$ unless otherwise stated. OR: Odds ratio; CI: confidence interval. ${ }^{*}$ : frequency in controls; ORHet (95\% CI): OR and $95 \% \mathrm{CI}$ for heterozygote genotype with risk allele; ORhom $(95 \% \mathrm{CI})$ : OR and 95\% CI for homozygote genotype with risk allele.

have been proposed [46] but these methods have yet to be applied widely and may be prone to overcorrection of potential biases. The family-based study design used in the present study provides a sampling procedure that avoids the potential bias of case-control sampling without making any elaborate statistical corrections.

In summary, the present study found no evidence for an association between sarcoidosis susceptibility in African Americans and three key genes, angiotensin converting enzyme, vitamin $\mathrm{D}$ receptor and tumour necrosis factor- $\alpha$, involved in granuloma formation. Overall results from past case-control studies of polymorphisms in these genes are equivocal with regard to sarcoidosis susceptibility. The results of the present study should not be subject to population stratification since potential confounding by genetic background was controlled in the study design. The current study was also sufficiently powered to detect levels of association with disease susceptibility that have been previously reported. The presented results suggest that genetic control of the granulomatous reaction is not related to sarcoidosis susceptibility in African Americans. Alternatively, the angiotensin converting enzyme, vitamin $\mathrm{D}$ receptor and tumour necrosis factor- $\alpha$ genes may not be optimal candidates for studying the sarcoidosis granulomatous reaction in relation to disease susceptibility in African Americans.

Acknowledgements. The authors thank all the study coordinators who helped with recruitment, including M. Major, T. Turpen, B. McLellan and W. Bibbs.

\section{References}

1. Rybicki BA, Iannuzzi MC, Frederick MM, et al. Familial aggregation of sarcoidosis. A case-control etiologic study of sarcoidosis (ACCESS). Am J Respir Crit Care Med 2001; 164: 2085-2091.
2. Rybicki BA, Kirkey KL, Major M, et al. Familial risk ratio of sarcoidosis in African-American sibs and parents. Am J Epidemiol 2001; 153: 188-193.

3. Rybicki BA, Major M, Popovich JJ, Maliarik MJ, Iannuzzi MC. Racial differences in sarcoidosis incidence: a 5-year study in a health maintenance organization. Am J Epidemiol 1997; 145: 234-241.

4. Silverstein E, Friedland J, Lyons HA, Gourin A. Markedly elevated angiotensin converting enzyme in lymph nodes containing non-necrotizing granulomas in sarcoidosis. Proc Natl Acad Sci USA 1976; 73: 2137-2141.

5. Silverstein E, Pertschuck LP, Freiedland J. Immunofluorescent localization of angiotensin converting enzyme in epithelioid and giant cells of sarcoidosis granuloma. Proc Natl Acad Sci USA 1979; 76: 6646-6648.

6. Rigat B, Hubert C, Alhenc-Gelas F, Cambien F, Corvol P, Soubrier F. An insertion/deletion polymorphisim in the angiotensin I converting enzyme gene accounting for half the variance of serum enzyme levels. J Clin Invest 1990; 86: 13431346.

7. Furuya K, Yamaguchi E, Itoh A, et al. Deletion polymorphism in the angiotensin I converting enzyme (ACE) gene as a genetic risk factor for sarcoidosis. Thorax 1996; 51: 777780 .

8. Maliarik MJ, Rybicki BA, Malvitz E, et al. Angiotensinconverting enzyme gene polymorphism and risk of sarcoidosis. Am J Respir Crit Care Med 1998; 158: 1566-1570.

9. Schurmann $\mathrm{M}$, Reichel $\mathrm{P}$, Muller-Myhsok $\mathrm{B}$, et al. Angiotensin-converting enzyme (ACE) gene polymorphisms and familial occurrence of sarcoidosis. J Intern Med 2001; 249: 77-83.

10. McGrath DS, Foley PJ, Petrek M, et al. Ace gene I/D polymorphism and sarcoidosis pulmonary disease severity. Am J Respir Crit Care Med 2001; 164: 197-201.

11. Arbustini E, Grasso M, Leo G, et al. Polymorphism of angiotensin-converting enzyme gene in sarcoidosis. $\mathrm{Am}$ J Respir Crit Care Med 1996; 153: 851-854.

12. Tomita $\mathrm{H}$, Ina $\mathrm{Y}$, Sugiura $\mathrm{Y}$, et al. Polymorphism in the angiotensin-converting enzyme (ACE) gene and sarcoidosis. Am J Respir Crit Care Med 1997; 156: 255-259. 
13. Shikama Y, Kobayashi K, Kasahara K, et al. Granuloma formation by artificial microparticles in vitro. Macrophages and monokines play a critical role in granuloma formation. Am J Pathol 1989; 134: 1189-1199.

14. Kaneshima H, Nagai S, Shimoji T, et al. TNF alpha mRNA, but not IL-1 beta, is differentially expressed in lung macrophages of patients with active pulmonary sarcoidosis. Sarcoidosis 1994; 11: 19-25.

15. Baughman RP, Iannuzzi M. Tumour necrosis factor in sarcoidosis and its potential for targeted therapy. BioDrugs 2003; 17: 425-431.

16. Allen RD. Polymorphism of the human TNF-alpha promoter-random variation or functional diversity? Mol Immunol 1999; 36: 1017-1027.

17. Grutters JC, Sato H, Pantelidis P, et al. Increased frequency of the uncommon tumor necrosis factor -857T allele in British and Dutch patients with sarcoidosis. Am J Respir Crit Care Med 2002; 165: 1119-1124.

18. Yamaguchi E, Itoh A, Hizawa N, Kawakami Y. The gene polymorphism of tumor necrosis factor-beta but not that of tumor necrosis factor-alpha, is associated with the prognosis of sarcoidosis. Chest 2001; 119: 753-761.

19. Seitzer U, Swider C, Stuber F, et al. Tumour necrosis factor alpha promoter gene polymorphism in sarcoidosis. Cytokine 1997; 9: 787-790.

20. Pandey JP, Frederick M. TNF-alpha, IL1-beta, and immunoglobulin (GM and KM) gene polymorphisms in sarcoidosis. Hum Immunol 2002; 63: 485-491.

21. Ohta M, Okabe T, Ozawa K, Urabe A, Takaku F. In vitro formation of macrophage-epithelioid cells and multinucleated giant cells by 1 alpha, 25-dihydroxyvitamin D3 from human circulating monocytes. Ann N Y Acad Sci 1986; 465: 211-220.

22. Sharma OP. Vitamin D, calcium, and sarcoidosis. Chest 1996; 109: 535-539.

23. Bell NH, Stern PH, Pantzer E, Sinha TK, DeLuca HF. Evidence that increased circulating 1 alpha, 25-dihydroxyvitamin $\mathrm{D}$ is the probable cause for abnormal calcium metabolism in sarcoidosis. J Clin Invest 1979; 64: 218-225.

24. Malloy PJ, Pike JW, Feldman D. The vitamin D receptor and the syndrome of hereditary 1,25-dihydroxyvitamin D-resistant rickets. Endocr Rev 1999; 20: 156-188.

25. Vidal M, Ramana CV, Dusso AS. Stat1-vitamin D receptor interactions antagonize 1, 25-dihydroxyvitamin D transcriptional activity and enhance stat1-mediated transcription. Mol Cell Biol 2002; 22: 2777-2787.

26. Zmuda JM, Cauley JA, Ferrell RE. Molecular epidemiology of vitamin D receptor gene variants. Epidemiol Rev 2000; 22: 203-217.

27. Niimi $\mathrm{T}$, Tomita $\mathrm{H}$, Sato $\mathrm{S}$, et al. Vitamin $\mathrm{D}$ receptor gene polymorphism in patients with sarcoidosis. Am J Respir Crit Care Med 1999; 160: 1107-1109.

28. Bell NH, Morrison NA, Nguyen TV, Eisman J, Hollis BW. ApaI polymorphisms of the vitamin D receptor predict bone density of the lumbar spine and not racial difference in bone density in young men. J Lab Clin Med 2001; 137: 133-140.

29. Whitfield GK, Remus LS, Jurutka PW, et al. Functionally relevant polymorphisms in the human nuclear vitamin D receptor gene. Mol Cell Endocrinol 2001; 177: 145-159.

30. Wilkinson RJ, Llewelyn M, Toossi Z, et al. Influence of vitamin D deficiency and vitamin D receptor polymorphisms on tuberculosis among Gujarati Asians in west London: a case-control study. Lancet 2000; 355: 618-621.

31. Schaid DJ, Rowland C. Use of parents, sibs, and unrelated controls for detection of associations between genetic markers and disease. Am J Hum Genet 1998; 63: 1492-1506.

32. Freedman ML, Reich D, Penney KL, et al. Assessing the impact of population stratification on genetic association studies. Nat Genet 2004; 36: 388-393.

33. Judson MA, Baughman RP, Teirstein AS, Terrin ML, Yeager H, Jr. Defining organ involvement in sarcoidosis: the ACCESS proposed instrument. ACCESS Research Group. A case control etiologic study of sarcoidosis. Sarcoidosis Vasc Diffuse Lung Dis 1999; 16: 75-86.

34. Laird NM, Horvath $\mathrm{S}, \mathrm{Xu} \mathrm{X}$. Implementing a unified approach to family-based tests of association. Genet Epidemiol 2000; 19: Suppl. 1, S36-S42.

35. Lange C, Laird NM. Power calculations for a general class of family-based association tests: dichotomous traits. Am J Hum Genet 2002; 71: 575-584.

36. Pietinalho A, Furuya K, Yamaguchi E, Kawakami Y, Selroos $\mathrm{O}$. The angiotensin-converting enzyme DD gene is associated with poor prognosis in Finnish sarcoidosis patients. Eur Respir J 1999; 13: 723-726.

37. Garrib A, Zhou W, Sherwood R, Peters TJ. Angiotensinconverting enzyme (ACE) gene polymorphism in patients with sarcoidosis. Biochem Soc Trans 1998; 26: S137.

38. Papadopoulos KI, Melander O, Orho-Melander M, Groop LC, Carlsson M, Hallengren B. Angiotensin converting enzyme (ACE) gene polymorphism in sarcoidosis in relation to associated autoimmune diseases. J Intern Med 2000; 247: 71-77.

39. Sharma P, Smith I, Maguire G, Stewart S, Shneerson J, Brown MJ. Clinical value of ACE genotyping in diagnosis of sarcoidosis. Lancet 1997; 349: 1602-1603.

40. Takemoto Y, Sakatani M, Takami S, et al. Association between angiotensin II receptor gene polymorphism and serum angiotensin converting enzyme (SACE) activity in patients with sarcoidosis. Thorax 1998; 53: 459-462.

41. Guleva I, Seitzer U. Vitamin D receptor gene polymorphism in patients with sarcoidosis. Am J Respir Crit Care Med 2000; 162: 760-761.

42. Swider C, Schnittger L, Bogunia-Kubik K, et al. TNF-alpha and HLA-DR genotyping as potential prognostic markers in pulmonary sarcoidosis. Eur Cytokine Netw 1999; 10: 143146.

43. Edmondstone WM, Wilson AG. Sarcoidosis in Caucasians, Blacks and Asians in London. Br J Dis Chest 1985; 79: 2736.

44. Roy S, Frodsham A, Saha B, Hazra SK, Mascie-Taylor CG, Hill AV. Association of vitamin D receptor genotype with leprosy type. J Infect Dis 1999; 179: 187-191.

45. Bellamy R, Ruwende C, Corrah T, et al. Tuberculosis and chronic hepatitis B virus infection in Africans and variation in the vitamin D receptor gene. J Infect Dis 1999; 179: 721724.

46. Pritchard JK, Stephens M, Rosenberg NA, Donnelly P. Association mapping in structured populations. Am J Hum Genet 2000; 67: 170-181. 